\title{
Polymerization of Unsaturated Sugars II. Radical Copolymerization of a Furanoid Glucal, 3-O- Benzyl-1,2-dideoxy-5,6-O-isopropylidene- D-arabino-hex-1-enofuranose
}

\author{
Yoshiyuki Koyama, Mitsuo Kawata, and Keisuke KurITA \\ Department of Industrial Chemistry, Faculty of Engineering, \\ Seikei University, Musashino-shi, Tokyo 180, Japan
}

(Received November 13, 1986)

\begin{abstract}
A stable furanoid glucal, 3- $O$-benzyl-1,2-dideoxy-5,6- $O$-isopropylidene-Darabino-hex-1-enofuranose (BIF) was synthesized, and the equilibrium association constant $\mathrm{K}$ for the charge-transfer complex formation with maleic anhydride in $\mathrm{CDCl}_{3}$ at $25^{\circ} \mathrm{C}$ was $0.131 \mathrm{~mol}^{-1}$ as determined by ${ }^{13} \mathrm{C}$ NMR. BIF copolymerized with maleic anhydride almost alternatingly, AIBN being used as the initiator. Other electron accepting monomers such as $N$-phenylmaleimide and acrylonitrile also copolymerized with BIF. Terpolymerization of BIF-maleic anhydrideacrylonitrile gave the copolymer containing BIF residues.

KEY WORDS Radical Copolymerization / Alternating Copolymerization / Unsaturated Sugar / Furanoid Glucal / Maleic Anhydride / Charge-Transfer Complex /
\end{abstract}

Many kinds of carbohydrate-containing polymers have been extensively studied, ${ }^{1,2}$ and reported to exhibit various interesting properties characteristic of natural polysaccharides, including high degrees of water absorption, ${ }^{3,4}$ rapid water flux through their membranes, ${ }^{4}$ and the interaction with lectins. $^{5,6}$ In the previous paper ${ }^{7}$ we described the radical copolymerization of pyranoid glucal derivatives with maleic anhydride, affording novel vinyl copolymers containing sugar residues in the main chain. However, the resulting copolymers had only low molecular weights presumably owing to steric hindrance at the propagation transition step. Furanoid glucals seem to be more appropriate to synthesize high molecular weight copolymers because of smaller steric hindrance of their five-membered ring structures.

In the present paper, we describe the preparation of a stable furanoid glucal, 3-O- benzyl-1,2-dideoxy-5,6- $O$-isopropylidene-Darabino-hex-1-enofuranose (BIF), and the charge-transfer complex polymerization with maleic anhydride and other electron acceptor monomers. Terpolymerization of BIF with maleic anhydride and acrylonitrile was also attempted.

\section{EXPERIMENTAL}

3-O-Benzyl-1,2-dideoxy-5,6-O-isopropylidene-D-arabino-hex-1-enofuranose (BIF)

1-Chloro-1-deoxy-2,3:5,6-di- $O$-isopropylidene- $\alpha$-D-mannose ${ }^{8}$ (37.5 g, $0.135 \mathrm{~mol}$ ) was reduced with sodium naphthalide in dry tetrahydrofuran as reported by Eitelman and coworkers $^{9}$ to give 1,2-dideoxy-5,6-O-isopropylidene-D-arabino-hex-1-enofuranose as an oily product. After purification by column chromatography, it was dissolved in $326 \mathrm{ml}$ of dimethylformamide and treated 
with $10.5 \mathrm{~g}$ of a $55 \% \mathrm{NaH}$ oil suspension $(0.24 \mathrm{~mol})$ and $30.4 \mathrm{~g}(0.24 \mathrm{~mol})$ of benzyl chloride as described for the preparation of 3,4,6-tri- $O$-benzyl-D-glucal. ${ }^{7}$ The crude product was distilled under vacuum and then chromatographed over silica gel with hexaneether (3:1 in volume) to give the pure 3-Obenzylated product (BIF) as a colorless liquid; $R f=0.44$. Yield $11.6 \mathrm{~g}(23.2 \%) ;$ bp $125-$ $128^{\circ} \mathrm{C} / 0.15 \mathrm{mmHg} ; \quad{ }^{1} \mathrm{H} \quad \mathrm{NMR} \quad\left(\mathrm{CDCl}_{3}\right)$ d 7.26-7.34 (m, 5H, aromatic $-\mathrm{CH}=), 6.62$ $(\mathrm{d}, J=2.7 \mathrm{~Hz}, 1 \mathrm{H}, \mathrm{H}-1), 5.28(\mathrm{t}, J=2.7 \mathrm{~Hz}, 1 \mathrm{H}$, $\mathrm{H}-2), 4.65$ (dd, $J=2.4,7.1 \mathrm{~Hz}, 1 \mathrm{H}, \mathrm{H}-3$ ), $4.41-4.62$ (m, 2H, H-4,5), 4.55, 4.53 (two s, $2 \mathrm{H}$, benzyl $-\mathrm{CH}_{2}-$ ), 4.11 (dd, $J=6.6,8.5 \mathrm{~Hz}$, $1 \mathrm{H}, \mathrm{H}-6), 3.99$ (dd, $J=6.6,8.5 \mathrm{~Hz}, 1 \mathrm{H}, \mathrm{H}-6)$, 1.47 , and $1.39 \mathrm{ppm}$ (two s, $6 \mathrm{H},-\mathrm{CH}_{3}$ ); ${ }^{13} \mathrm{C}$ NMR $\left(\mathrm{CDCl}_{3}\right) \delta: 150.49$ (C-1), 138.41, 128.31, $127.53,127.47$ (aromatic), 108.66 (acetal), 101.86 (C-2), 84.13, 79.26, 71.01 (C-3, 4, 5), 73.10 (benzyl- $\mathrm{CH}_{2}-$ ), 66.00 (C-6), 26.51, and $25.25 \mathrm{ppm} \quad\left(-\mathrm{CH}_{3}\right) ;$ IR $(\mathrm{KBr}) \quad 1605 \mathrm{~cm}^{-1}$ $(\mathrm{C}=\mathrm{C})$.

\section{Radical Copolymerization of BIF}

Copolymerization was carried out under vacuum in a sealed glass ampul using 2,2'azobisisobutyronitrile (AIBN) as the initiator. Copolymers were purified by three reprecipitations with the acetone and ether-hexane $(1: 1)$ system and dried under vacuum.

\section{Determination of Copolymer and Terpolymer Compositions}

The copolymer composition was determined from the relative areas of the methyl protons of the copolymer and those of the internal reference, dimethyl phthalate, in the ${ }^{1} \mathrm{H}$ NMR spectrum in $\mathrm{CDCl}_{3}$.

The composition of the BIF-MAnh-AN terpolymer was determined by carrying out the polymerization in benzene- $d_{6}$ in an NMR sample tube and by comparing the peak area of the vinyl protons of each monomer with that of the phenyl protons of $p$-dimethoxybenzene as the reference.

\section{Measurements}

${ }^{1} \mathrm{H}$ and ${ }^{13} \mathrm{C}$ NMR spectra were measured with a JEOL JNM-GX270 operated at 270 and $68 \mathrm{MHz}$, respectively, using tetramethylsilane as the internal reference. Gel permeation chromatograms were measured on the polymer solutions in tetrahydrofuran with a JASCO HPLC BIP-I (column: Shodex GPC AD-803/s and AD-805/s), and number average molecular weights were calculated with polystyrene standards.

\section{RESULTS AND DISCUSSION}

Benzylation of 1,2-dideoxy-5,6- $O$-isopropylidene-D-arabino-hex-1-enofuranose was carried out with $\mathrm{NaH}$ and benzyl chloride in dimethylformamide to give 3-O-benzyl-1,2dideoxy-5,6- $O$-isopropylidene-D-arabino-hex1-enofuranose (BIF), which was purified by vacuum distillation and column chromatography. It is a stable colorless liquid, and can be stored at room temperature over several months.

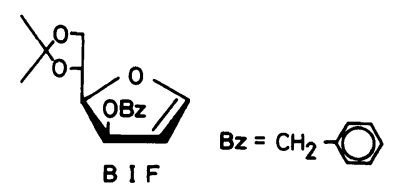

Determination of the Equilibrium Constant for the Charge-Transfer Complex Formation between BIF and Maleic Anhydride (MAnh)

The ${ }^{13} \mathrm{C}$ NMR spectra were measured on $\mathrm{CDCl}_{3}$ solutions containing varying ratios of BIF to MAnh. The equilibrium constant $K$ for the charge-transfer complex formation was determined at $25^{\circ} \mathrm{C}$ by means of eq 1 derived by Foster and Fyfe. ${ }^{10}$ When $[\mathrm{A}] \gg[\mathrm{D}]$,

$$
\frac{\Delta}{[\mathrm{A}]}=-\Delta \cdot K+\Delta_{0} \cdot K
$$

where $\Delta=\delta_{\mathrm{obs}}^{\mathrm{D}}-\delta_{0}^{\mathrm{D}}, \quad \Delta_{0}=\delta_{\mathrm{AD}}^{\mathrm{D}}-\delta_{0}^{\mathrm{D}}$,

[A] and [D] are concentrations of the acceptor monomer, MAnh, and donor monomer, BIF, 
respectively, $\delta_{0}^{\mathrm{D}}$ is the chemical shift of the C-1 carbon of free BIF, $\delta_{\mathrm{AD}}^{\mathrm{D}}$, that in the complex, and $\delta_{\text {obs }}^{\mathrm{D}}$, the observed shift in the mixture system. The results are shown in Figure 1. The $K$ value obtained as the negative slope of the line is $0.131 \mathrm{~mol}^{-1}$. Since eq 1 is applicable to the case of $1: 1$ complex formation, the linear

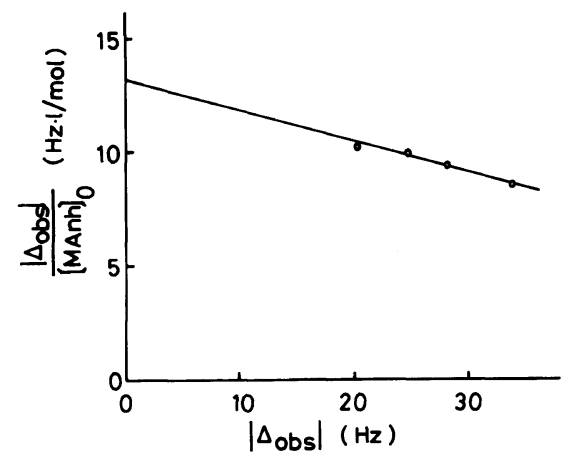

Figure 1. Plot of $\Delta /[\mathrm{MAnh}]$ against $\Delta$ for the complex of BIF with MAnh in $\mathrm{CDCl}_{3}$ at $25^{\circ} \mathrm{C}$. relationship between $\Delta /[\mathrm{A}]$ and $\Delta$ shown in the figure indicates the formation of the $1: 1$ BIF/MAnh complex.

\section{Copolymerization of BIF with MAnh}

BIF was copolymerized with MAnh as a typical acceptor monomer at a monomer feed ratio of $1: 1$. The results are summarized in Table I. Copolymerization of BIF and MAnh without any initiator at $60^{\circ} \mathrm{C}$ for $8 \mathrm{~h}$ gave no polymer. When a radical initiator, AIBN, was added, copolymerization proceeded homogeneously in benzene, dichloromethane, acetone, or bulk, and white powdery copolymers were obtained. They were soluble in benzene, acetone, tetrahydrofuran, and dimethyl sulfoxide, and insoluble in hexane, ether, and water. The IR spectra of the polymers showed absorptions due to both acid anhydride $\left(1770-1860 \mathrm{~cm}^{-1}\right)$ and cyclic ether $(1000-$ $\left.1100 \mathrm{~cm}^{-1}\right)$, supporting the formation of co-

Table I. Copolymerization of BIF $\left(M_{1}\right)$ with MAnh $\left(M_{2}\right)^{a}$

\begin{tabular}{ccclccc}
\hline No. & $\begin{array}{c}\mathrm{M}_{1} \\
\text { in } \mathrm{mmol}\end{array}$ & $\begin{array}{c}\text { AIBN } \\
\text { in } \times 10^{-2} \mathrm{mmol}\end{array}$ & Solvent/ml & $\begin{array}{c}\text { Time } \\
\text { in h }\end{array}$ & $\begin{array}{c}\text { Conversion } \\
\text { in wt } \%\end{array}$ & $\bar{M}_{n}$ \\
\hline 1 & 0.84 & 4 & None & 24 & 31.0 & 3950 \\
2 & 1.00 & 4 & None & 48 & 32.8 & 4180 \\
3 & 0.87 & 0 & Benzene (0.5) & 24 & 0 & 5160 \\
4 & 1.01 & 2 & Benzene (0.5) & 24 & 13.4 & 5410 \\
5 & 0.91 & 4 & Benzene (0.5) & 24 & 25.6 & 4390 \\
6 & 0.76 & 4 & Benzene (0.5) & 48 & 39.4 & 4550 \\
7 & 1.06 & 4 & $\mathrm{CH}_{2} \mathrm{Cl}_{2}(0.5)$ & 24 & 23.7 & 4 \\
8 & 0.95 & 4 & Acetone (0.5) & 24 & 28.2 & 4650 \\
\hline
\end{tabular}

${ }^{a}\left[\mathrm{M}_{1}\right]=\left[\mathrm{M}_{2}\right]$, at $60^{\circ} \mathrm{C}$.

Table II. Copolymerization of BIF $\left(M_{1}\right)$ with MAnh $\left(M_{2}\right)$ at various monomer feed ratios ${ }^{a}$

\begin{tabular}{|c|c|c|c|c|c|c|}
\hline \multirow[b]{2}{*}{ No. } & \multirow[b]{2}{*}{$\begin{array}{c}\mathrm{M}_{1} \\
\text { in } \mathrm{mol}^{\circ} \%\end{array}$} & \multirow[b]{2}{*}{$\begin{array}{c}\mathbf{M}_{2} \\
\text { in } \mathrm{mol} \%\end{array}$} & \multirow[b]{2}{*}{$\begin{array}{l}\text { Conversion } \\
\text { in } \mathrm{wt}^{\circ} \%\end{array}$} & \multicolumn{2}{|c|}{ Copolymer composition } & \multirow[b]{2}{*}{$\overline{\mathrm{DPn}}$} \\
\hline & & & & $\begin{array}{c}\mathrm{M}_{1} \\
\text { in } \mathrm{mol}^{\mathrm{o}} \%\end{array}$ & $\begin{array}{c}\mathrm{M}_{2} \\
\text { in } \mathrm{mol} \%\end{array}$ & \\
\hline 9 & 25.0 & 75.0 & 31.3 & 50.2 & 49.8 & 16.6 \\
\hline 10 & 37.5 & 62.5 & 23.2 & 54.1 & 45.9 & 25.2 \\
\hline 11 & 50.0 & 50.0 & 22.1 & 55.6 & 44.4 & 28.2 \\
\hline 12 & 62.5 & 37.5 & 14.9 & 52.1 & 47.9 & 31.4 \\
\hline 13 & 75.0 & 25.0 & 13.1 & 58.3 & 41.7 & 35.1 \\
\hline
\end{tabular}

\footnotetext{
a $\left[M_{1}\right]+\left[M_{2}\right]=2 \mathrm{moll}^{-1}$ in benzene, AIBN: $4 \times 10^{-2} \mathrm{moll}^{-1}$, at $60^{\circ} \mathrm{C}$ for $18 \mathrm{~h}$.
} 
polymers from BIF and MAnh.

The number-average molecular weights of the copolymers determined by GPC were in a range 4000-5400. These values are lower than those of ordinary vinyl ether-MAnh copolymers, probably on account of steric hindrance in the porpagation transition state. They were, however, higher than those of the copolymers derived from pyranoid glucals. ${ }^{7}$ This may be interpreted in terms of the relatively lower steric hindrance of the fivemembered ring structure of BIF than the sixmembered ones.

Copolymerization of BIF with MAnh was then carried out at various monomer feed ratios. The results are given in Table II. Figure 2 shows a plot of copolymer compositions. This plot is a good indication of the occurrence of alternating copolymerization, since both BIF and MAnh do not homopolymerize under these conditions.

For the analysis of the copolymerization of a pyranoid glucal and MAnh, the complex model was shown to be more appropriate than the penultimate model, ${ }^{7}$ and thus the complex model was applied for the copolymerization of BIF and MAnh. According to the complex model analysis which considers the participation of the charge-transfer complex of donor and acceptor monomers, each propagation

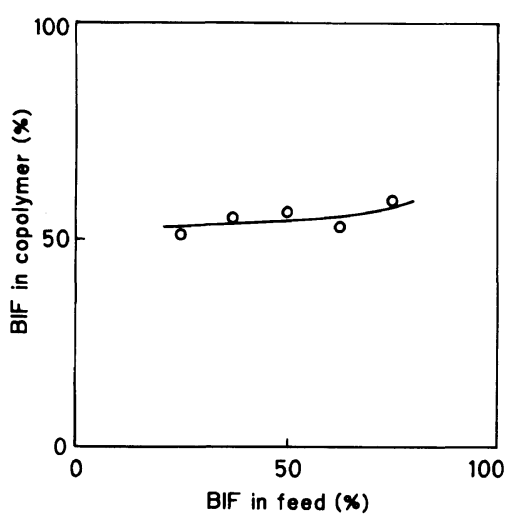

Figure 2. Composition diagrams of the copolymerization of BIF with MAnh. $\bigcirc$, experimental results; solid line, calculated with $P=0.6, Q=3.8, R=0$, and $S=0$. step can be expressed as

$$
\begin{aligned}
& \sim \mathrm{B} \cdot+\mathrm{B} \stackrel{k_{11}}{\longrightarrow} \sim \mathrm{B} . \\
& \sim \mathrm{B} \cdot+\mathrm{C} \stackrel{k_{1 \mathrm{C}}}{\longrightarrow} \sim \mathrm{C} . \\
& \sim \mathrm{B} \cdot+\mathrm{M} \stackrel{k_{12}}{\longrightarrow} \sim \mathrm{M} . \\
& \sim \mathrm{M} \cdot+\mathrm{B} \stackrel{k_{21}}{\longrightarrow} \sim \mathrm{B} . \\
& \sim \mathrm{M} \cdot+\mathrm{C} \stackrel{k_{2 \mathrm{C}}}{\longrightarrow} \sim \mathrm{M} . \\
& \sim \mathrm{M} \cdot+\mathrm{M} \stackrel{k_{22}}{\longrightarrow} \sim \mathrm{M} .
\end{aligned}
$$

where $\mathbf{B}, \mathbf{M}$, and $\mathrm{C}$ represent $\mathrm{BIF}, \mathrm{MAnh}$, and the BIF-MAnh complex, respectively. Assuming the stationary-state, the following relationship was obtained.

$$
\frac{\mathrm{d}[\mathrm{B}]}{\mathrm{d}[\mathrm{M}]}=\frac{P \frac{[\mathrm{B}]}{[\mathrm{M}]}+Q[\mathrm{~B}]+R[\mathrm{M}]+1}{Q[\mathrm{~B}]+R[\mathrm{M}]+S \frac{[\mathrm{M}]}{[\mathrm{B}]}+1}
$$

where $P=k_{11} / k_{12}, Q=k_{1 \mathrm{C}} K / k_{12}, R=k_{2 \mathrm{C}} K / k_{21}$, and $S=k_{22} / k_{21} . \Delta[\mathrm{B}] / \Delta[\mathrm{M}]$ was calculated by putting various values in the places of $Q, R$, and $S$, and assuming the $P$ values to be $0-1.0$ by means of numeral integration. The values of $Q, R$, and $S$ which best fit the experimental data were obtained for each $P$ value assumed. For example,

$Q=2.3, \quad R=0, \quad S=0, \quad$ assuming $P=0.4$ $Q=3.8, \quad R=0, \quad S=0, \quad$ assuming $P=0.6$ $Q=5.4, \quad R=0, \quad S=0$, assuming $P=0.8$

The compositions calculated with the sets of values based on $0.3 \leqq P \leqq 1$ agreed with the experimental results within a deviation of $2.5 \%$. It was, however, difficult to determine which set is the most suitable from these results. The solid line in Figure 2 shows the results of the calculation with $P=0.6, Q=3.8$, $R=0$, and $S=0$ as a typical example. When the $P$ value is assumed to be less than 0.3 , the $Q, R$, and $S$ values fitting the compositional data within a $2.5 \%$ deviation could not be found. Both the $R$ and $S$ values should be almost zero so as to make calculated compositions fit with the experimental results, indicating the charge-transfer complex to react predominantly with the macroradical bearing a BIF end unit, and the MAnh radical not to 
Radical Copolymerization of a Furanoid Glucal

Table III. Copolymerization of BIF $\left(\mathbf{M}_{1}\right)$ with other acceptor monomers $\left(\mathbf{M}_{2}\right)^{\mathbf{a}}$

\begin{tabular}{|c|c|c|c|c|c|c|c|}
\hline No. & \multicolumn{2}{|c|}{$\mathrm{M}_{2} / \mathrm{mmol}$} & Solvent $/ \mathrm{ml}$ & $\begin{array}{l}\text { Time } \\
\text { in } h\end{array}$ & $\begin{array}{l}\text { Conversion } \\
\text { in } \mathrm{wt}^{\circ} \%\end{array}$ & $\begin{array}{c}\mathrm{M}_{1} \text { in copolymer } \\
\text { in } \mathrm{mol} \%\end{array}$ & $\bar{M}_{n}$ \\
\hline 14 & TCNQ & $(0.79)$ & EtOAc (15) & 24 & 0 & & \\
\hline 15 & $p$-Chloranil & $(0.84)$ & Benzene (3) & 24 & 0 & & \\
\hline 16 & MMA & (1.46) & Benzene (1) & 8 & 20.2 & 0 & \\
\hline 17 & PhMI & $(0.86)$ & Benzene (1) & 24 & 56.9 & 31.4 & 10870 \\
\hline 18 & AN & $(1.01)$ & Benzene (1) & 8 & 6.7 & 9.9 & $-^{\mathbf{b}}$ \\
\hline
\end{tabular}

a $\left[\mathrm{M}_{1}\right]=\left[\mathrm{M}_{2}\right]$, AIBN: $4 \times 10^{-2} \mathrm{mmol}$, at $60^{\circ} \mathrm{C}$.

b Insoluble in tetrahydrofuran.

Table IV. Terpolymerization of BIF, MAnh, and $\mathrm{AN}^{\mathrm{a}}$

\begin{tabular}{cccccccccc}
\hline No. & $\begin{array}{c}\text { BIF } \\
\text { in mmol }\end{array}$ & $\begin{array}{c}\text { MAnh } \\
\text { in mmol }\end{array}$ & $\begin{array}{c}\text { AN } \\
\text { in mol }\end{array}$ & $\begin{array}{c}\text { Total } \\
\text { volume } \\
\text { in } \mathrm{ml}\end{array}$ & $\begin{array}{c}\text { Time } \\
\text { in } \mathrm{h}\end{array}$ & $\begin{array}{c}\text { Conversion } \\
\text { in wt } \%\end{array}$ & $\begin{array}{c}\text { Copolymer composition } \\
\text { in mol } \%\end{array}$ & $\begin{array}{c}\text { MAnh } \\
\text { in mol } \%\end{array}$ & $\begin{array}{c}\text { AN } \\
\text { in mol } \%\end{array}$ \\
\hline 19 & 1.01 & 1.01 & 0.334 & 1 & 6 & 39.4 & 53.0 & 39.5 & 7.4 \\
20 & 1.01 & 1.01 & 0.340 & 3 & 12 & 40.3 & 58.3 & 35.5 & 6.2 \\
\hline
\end{tabular}

a Solvent, benzene- $d_{6} 1 \mathrm{ml}$, AIBN: $4 \times 10^{-2} \mathrm{mmol}$, at $60^{\circ} \mathrm{C}$.

react with MAnh monomer.

\section{Copolymerization of BIF with Other Acceptor} Monomers

Copolymerizations of BIF with other monomers, tetracyanoquinodimethane (TCNQ), p-chloranil, $\quad N$-phenylmaleimide (PhMI), methyl methacrylate (MMA), and acrylonitrile (AN) were carried out at $60^{\circ} \mathrm{C}$ in the presence of AIBN. As shown in Table III, BIF copolymerized with PhMI or AN into white powdery polymers containing 31.4 $\mathrm{mol} \%$ and $9.9 \mathrm{~mol} \%$ BIF residues, respectively, at a $1: 1$ monomer feed ratio. The reaction of BIF with TCNQ and $p$-chloranil did not yield any polymeric product. In the BIF/MMA system, BIF was not incorporated in the polymer, and only homopoly(MMA) was obtained.

Terpolymerization of BIF, MAnh, and MMA or $A N$

Terpolymerization of BIF, MAnh, and MMA (1:1:1 molar feed ratio) was also at- tempted with AIBN. The resulting polymer, however, had no BIF residue and was a binary copolymer of MAnh and MMA.

A BIF-containing copolymer could be obtained by terpolymerization of BIF, MAnh, and $\mathrm{AN}$ in benzene. The terpolymerization was then carried out in benzene- $d_{6}$ to determine the composition of the resulting polymer by measuring the concentrations of the residual monomers by ${ }^{1} \mathrm{H}$ NMR spectroscopy, using $p$-dimethoxybenzene as the internal reference. The results are summarized in Table IV. On decreasing the monomer concentration, the BIF content and BIF/MAnh ratio in the polymer increased, while the AN content decreased slightly. The decrease in the AN content seems to be in conflict with the presumption that the $\mathrm{AN} /$ complex ratio increases on dilution, since the concentration of the complex from BIF and MAnh decreases in the second order with respect to the monomers. However, such a phenomenon has often been observed and can be explained in terms of solvation of the complex which affects the 
reactivity. ${ }^{11}$

\section{REFERENCES}

1. K. Kobayashi and H. Sumitomo, Macromolecules, 13, 234 (1980).

2. T. P. Bird, W. A. Black, J. A. Colquhoun, E. T. Dewar, and D. Rutherford, J. Chem. Soc., Sect. C, 1913 (1966).

3. K. Kurita, N. Hirakawa, and Y. Iwakura, Makromol. Chem., 180, 2331 (1979).

4. G. Maconochie, A. Sharples, and G. Thompson, Eur. Polym. J., 7, 499 (1971).

5. K. Kobayashi, H. Sumitomo, and Y. Ina, Polym. J.,
17, 567 (1985).

6. Y. Koyama, A. Yoshida, and K. Kurita, Polym. J., 18, 479 (1986).

7. Y. Koyama, M. Kawata, and K. Kurita, Polym. J., 19, 687 (1987).

8. K. Freundenberg, A. Wolf, E. Knopf, and S. Zaheer, Ber. Bunsenges. Phys. Chem., 61, 1743 (1982).

9. S. J. Eitelman, R. H. Hall, and A. Jordaan, J. Chem. Soc., Parkin Trans. 1, 595 (1978).

10. R. Foster and C. A. Fyfe, Trans. Faraday Soc., 61, 1626 (1965).

11. S. Iwatsuki and Y. Yamashita, J. Polym. Sci., A-1, 5, 1753 (1967). 